\title{
SHONICNO (SMART GARDEN HOME AQUAPONIC BASED ARDUINO)
}

\author{
Fahmi Ulin Nuha $^{\# 1}$, Zazid Abdul Rizal ${ }^{* 2}$, Dina Desi Permatasari ${ }^{\# 3}$ \\ \# Jurusan Teknologi Informasi,Politeknik Negeri Jember \\ Jalan Mastrip Kotak Pos 164 Sumbersari, Jember 68101 \\ ${ }^{1}$ fahmiulinnuha07@gmail.com \\ 2zazidlupuz@gmail.com \\ ${ }^{3}$ dinadesipermatasari@gmail.com
}

\begin{abstract}
Aquaponics is a modern system that has been widely applied. This aquaponics system is applied to Shonicno (home aquaponik based arduino smart garden) which aims to facilitate its application in the family scope and increase enthusiasm in farming and fish farming due to lack of time to care for plants as well as narrow land. Users of this system can choose plants, from vegetable and ornamental plants, fish in the aquarium can also be filled with ornamental fish or fish for consumption. Shonicno uses an automation system that works automatically using the Arduino microcontroller as a controller of shonicno. Automation systems include regulation of temperature, humidity, fish feed and substitution of sunlight that plants need and as output of this system is displayed on the Nokia LCD. Shinonicno monitoring is assisted from the performance of additional sensors installed on a device with a wireless connection. The entire work of the device is programmed through the Arduino compiler and planted in the brain of the device to become an embedded system (embedded system). Facilities at Shonicno make it easier for families to control crop cultivation, fish cultivation and for home decoration.
\end{abstract}

Keywords - Akuaponik, Embedded System, Arduino, Otomasi, Smart garden.

\section{PENDAhuluan}

Berdasarkan luas lahan sawah di Jawa Timur dalam tiga tahun terakhir mengalami penurunan. Pada tahun 2015 luas lahan sawah bernilai 1.091.752 (ha). Luas lahan yang semakin berkurang mengakibatkan menurunnya produksi pangan, mengancam keseimbangan ekosistem, berkurangnya lahan pertanian dan tingginya harga pangan.

Teknologi saat ini berperan hampir pada semua bidang informasi, ekonomi, sosial, pendidikan, militer, kesehatan, perikanan dan pertanian. Peranan teknologi sangat membantu manusia dalam melakukan bidang pekerjaannya sehingga dapat menambah produktivitas, kuantitas dan kualitas hasil yang ingin dicapai. Teknologi sangat efektif untuk diterapkan dalam kehidupan masyarakat terutama keluarga. Keluarga sangat berpotensi untuk menunjang kesejahteraan daerah sehingga terciptanya daerah dengan kualitas masyarakat yang mandiri.

Peranan teknologi dalam kehidupan keluarga dapat diterapkan pada area rumah, seperti berkebun dan membuat taman sederhana. Teknologi ini dapat diterapkan untuk pemanfaatan lahan, proses perawatan serta perkembangan benih sampai tumbuh dan berkembang menjadi tanaman. Hal ini dapat menambah keluarga untuk membuat taman dan membuat lingkungan hijau.

Berdasarkan permasalahan tersebut kami memiliki sebuah terobosan inovatif untuk pembuatan taman dengan sistem akuaponik. Akuaponik merupakan gabungan teknologi akuakultur dengan teknologi hydroponic dalam satu sistem untuk mengoptimalkan fungsi air dan ruang sebagai media pemeliharaan. Sistem ini juga dilengkapi dengan menerapkan teknologi otomasi untuk kontrol tanaman secara otomatis.

Monitoring dan otomasi ini dilakukan mulai dari pencahayaan, suhu, pakan ikan dan kelembapan. Penerapan teknologi otomasi ini pada taman yang area kecil dan untuk mengatasi kurangnya waktu perawatan. Maka dengan sistem ini berdampak baik yaitu mempunyai nilai jual dan juga bisa mempercantik rumah.

\section{TinjauAn PUSTAKa}

A. Akuaponik 
Akuaponik merupakan cara bercocok tanam yang menggabungkan akuakultur dan hidroponik, tujuannya adalah untuk memelihara ikan serta tanaman dalam lingkungan yang tersirkulasi dan sistem yang saling terhubung. Interaksi antara ikan dan tanaman menghasilkan hubungan yang saling menguntungkan. Kotoran ikan memberikan nutrisi pada tanaman sedangkan tanaman berfungsi sebagai filter bagi amonia dan senyawa nitrogen lainnya dari air, sehingga air yang tersikulasi kembali menjadi aman bagi ikan.

Menurut Diver (2006) Dalam perkembangannya sistem ini mengalami banyak kendala tapi pada tahun 1990 sistem ini berkembang luas walaupun banyak kegagalan.

B. Arduino

Arduino dikatakan sebagai sebuah platform dari physical computing yang bersifat open source. Pertama-tama perlu dipahami bahwa kata "platform" di sini adalah sebuah pilihan kata yang tepat. Arduino tidak hanya sekedar sebuah alat pengembangan, tetapi arduino adalah kombinasi dari hardware, bahasa pemrograman dan Integrated Development Environment (IDE) yang canggih. IDE adalah sebuah software yang sangat berperan untuk menulis program, meng-compile menjadi kode biner dan meng-upload ke dalam memory microcontroller. Ada banyak projek dan alat-alat dikembangkan oleh akademisi dan profesional dengan menggunakan Arduino, selain itu juga ada banyak modul-modul pendukung (sensor, tampilan, penggerak dan sebagainya) yang dibuat oleh pihak lain untuk bisa disambungkan dengan Arduino. Arduino berevolusi menjadi sebuah platform karena ia menjadi pilihan dan acuan bagi banyak praktisi. (Feri Djuandi,2011). C. Sistem tertanam (Embedded System)

Embedded-system adalah sebuah sistem, yang terdiri dari dua sub-sistem atau lebih bersifat otonom, berbasiskan mikroprosesor yang dibangun untuk mengontrol suatu fungsi atau domain kerja suatu fungsi, dan tidak didesain untuk diprogram oleh enduser seperti pada PC (komputer). Dasar dan pengembangan embedded-system adalah: bidang komputer hardware, bidang mikroelektronika, dan bidang telekomunikasi. (S.N.M.P. Simamora, Diani Renita Rahmalia, Mohammad Dani, 2012).

Embedded system merupakan sebuah sistem (rangkaian elektronik) digital yang merupakan bagian dari sebuah sistem yang lebih besar, yang biasanya bukan sistem elektronik. Kata (Embedded) menunjukkan bahwa dia merupakan bagian yang tidak dapat berdiri sendiri. Embedded system biasanya merupakan application-specific system yang didesain khusus untuk aplikasi tertentu. Embedded system dapat memberikan respon yang sifatnya real time. Embedded system banyak digunakan pada peralatan digital.

\section{TCP/IP}

TCP/IP (Transmission Control Protocol/Internet Protocol) adalah standar komunikasi data yang digunakan oleh internet dalam proses tukar menukar data dari komputer ke komputer lain di dalam jaringan internet. Protokol ini tidaklah dapat berdiri sendiri, karena memang protocol ini berupa kumpulan protokol (protocol suite). Protokol ini juga merupakan protokol yang paling banyak digunakan saat ini. Data tersebut diimplementasikan kedalam bentuk perangkat lunak (software) disistem operasi. Istilah yang diberikan perangkat lunak ini adalah TCP/IP stack.[11]

\section{Metode Penelitian}

Penelitian ini terdiri dari tiga tahapan yaitu input, proses dan output seperti gambar 3.1

\section{Diagram Blok}

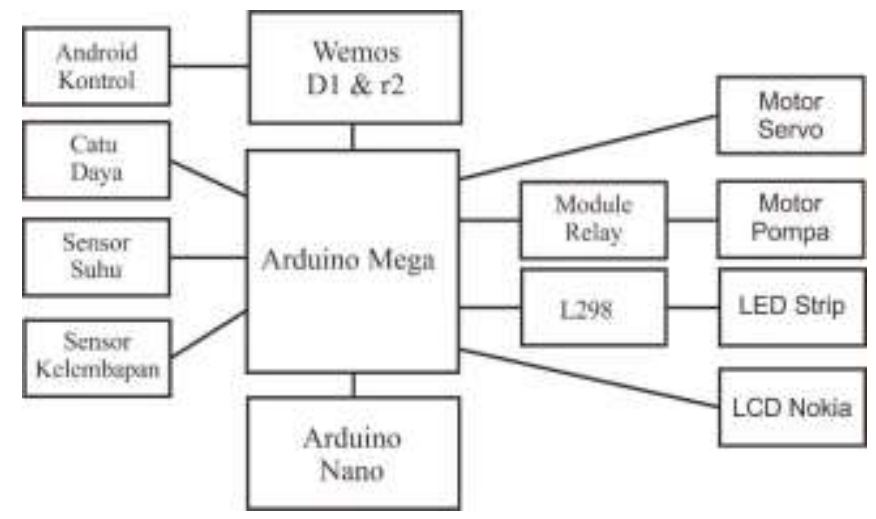

Gambar 3.1 Alur sistem

Pada blok diagram dapat dijelaskan proses dari catu daya sebagai penyedia tegangan. Alat ini tersambung pada shield arduino mega. Arduino mega merupakan pengontrol dari semua rangkaian yang tersambung dan juga sebagai otak dari sistem ini. Arduino mega tersambung pada sensor suhu dan kelembapan. Hasil dari kedua sensor tersebut di tampilkan pada LCD Nokia. Nilai kelembapan yang kurang maka akan mengaktifkan pompa dan 
mematikan lampu. Arduino mega juga yang mengatur jadwal harian mulai dari memberi makan ikan dan menyiram tanaman.

\section{Hasil Dan Pembahasan}

\section{A. Smart Garden}

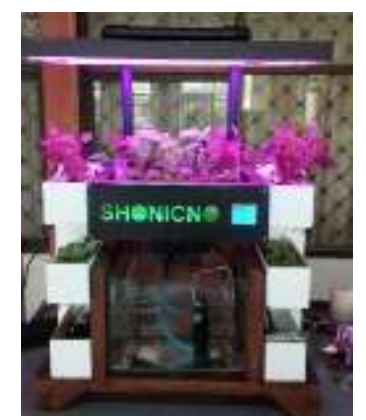

Hasil dari pembuatan Shonicno (smart garden home aquaponic based arduino) dapat di lihat dari kinerja yang telah di program. Pemograman pada arduino merupakan penerapan smart garden melalui perintah source code yang di lakukan pada arduino. Arduino yang dipakai untuk mengatur smart garden yang diterapkan yaitu arduino mega menggunakan komunikasi serial dengan arduino nano yang berfungsi sebagai kerja rutintas setiap harinya. Smart garden yang diterapkan sebagai berikut:

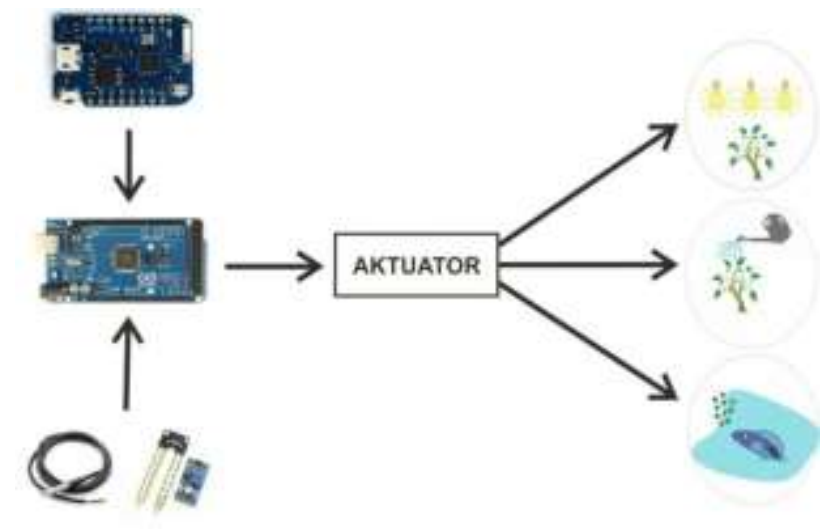

Gambar 4.1 Sistem kerja alat

1) Kontrol Suhu dan Kelembapan

Pada gambar 4.1 dijelaskaan otak dari sistem pengaturan smart garden yaitu arduino mega, sensor yang terpasang pada arduino menjadi input arduino mega. Terdapat dua sensor yaitu sensor suhu dan sensor kelembapan, kedua sensor tersebut mengirim data yang diperoleh sebagai acuan tindakan yang akan dilakukan oleh arduino mega, ketika sensor menunjukan suhu yang tinggi dan kelembapan yang kurang maka aktuator akan mengaktifkan pompa dan led untuk menyiram tanaman selama 4 detik dan mematikan lampu penerangan sampai suhu aman dan kelembapan terpenuhi. Suhu dan kelembapan akan terus di monitoring karena akan berpengaruh pada tanaman. Suhu yang tinggi dan kelembapan yang tidak sesuai maka akan berdampak negatif pada tanaman, pengolahan tersebut dikontrol oleh arduino mega sebagai sistem pengaturan pada shonicno. Sensor DS18B20 digunakan untuk mengukur suhu pada area sekitar dan suhu media tanam yang digunakan. Sensor DS18B20 merupakan sensor digital yang memiliki 12-bit ADC internal. Sangat presisi, sebab jika tegangan referensi sebesar 5 volt, maka akibat perubahan suhu, ia dapat merasakan perubahan terkecil sebesar $5 /(212-1)=0.0012$ Volt ! Pada rentang suhu -10 sampai +85 derajat Celcius, sensor ini memiliki akurasi +/-0.5 derajat. Sensor ini bekerja menggunakan protokol komunikasi 1wire (one-wire).

2) Sistem Penjadwalan Shonicno

Pengaturan rutinitas dilakukan setiap hari yaitu menyiram tanaman, pergantian warna penyinaran untuk tanaman dan pemberian pakan ikan. Sistem pengaturan ini dilakukan dengan bantuan arduino sebagai pengolah jadwal rutinitas yang dilakukan. Arduino nano meberikan sinyal low pada pin yang telah di atur sebagai input dari arduino mega untuk melakukan rutinitas program. Penyiraman tanaman dilakukan 1 jam sekali dengan lama penyiraman selama 4 detik. Sumber yang di ambil yaitu pada aquarium yang berisi ikan, Kotoran ikan akan menjadi nutrisi bagi tanaman dan air akan kembali jernih setelah melewati penyaringan pada media tanam yang dipakai. Pergantian warna Penyinaran yang dilakukan pada rutinitas shonicno dilakukan karena akan berpengaruh pada tanaman, warna yang berbeda akan mengasilkan gelombang yang bebeda juga.

Pemberian pakan ikan dengan aktuaktor yang digunakan yaitu motor servo sebagai pembuka dan penutup tempat pakan ikan. Pemberian pakan dilakukan 3 kali dalam sehari dengan jeda 8 jam, sesuai dengan jumlah ikan yang ada di aquarium. Informasi rutinitas dapat di lihat juga dengan secara langsung maupun dengan notifikasi, Pengguna dapat mengetahui keadaan pada shonicno melalui led notification yang berfungsi untuk menampilan suhu dan 
kelembapan. LCD juga dapat disetting untuk meampilkan animasi dan informasi lainnya seperti wajah pengguna, animasi gerakan dan notifikasi pakan ikan telah habis.

3) Kontrol android

Rutinitas yang dilakukan Shonicno merupakan smart garden yang diterapkan dan dikontrol langsung melauli otak dari Shonicno sendiri yaitu arduino mega, smart garden juga ditambah dengan kontrol melalaui android. Android terkoneksi dengan shonicno melalui wifi dengan menerapkan aplikasi untuk mengkontrol shonicno dengan mengirim data intruksi, Koneksi berjalan di protokol TCP/IP dengan shonicno juga terkoneksi pada wifi melalui komponen Wemos D1 R2. Wemos digunakan sebagai penerima data dari pengiriman melalui aplikasi android, wemos merima dan mengirim data tersebut melaui koneksi serial, data tersebut akan menjadi input bagi Arduino mega dalam melakasakan intruksi yang diberikan. Manfaatnya pengguna dapat mengkontrol shonicno dari jarak jauh dan dapat langsung menggunakannya, tanpa harus datang pada tempatnya secara langsung.

4.2 Hasil Uji Alat

\begin{tabular}{|r|c|c|c|c|c|}
\hline \multirow{2}{*}{ No } & \multirow{2}{*}{ Hari } & \multicolumn{3}{|c|}{ Tanaman } & Ikan \\
\cline { 3 - 4 } & & Pakcoy & $\begin{array}{c}\text { Bayam } \\
\text { Merah }\end{array}$ & Selada \\
S & & \\
\hline
\end{tabular}

\begin{tabular}{|c|c|c|c|c|c|c|c|}
\hline 1 & Minggu & Hidup & Hidup & Hidup & Hidup & $\operatorname{tron} D$ & 71, Nov. \\
\hline 2 & Senin & Hidup & Hidup & Hidup & Hidup & & \\
\hline 3 & Selasa & Hidup & Hidup & Hidup & Hidup & & . von der Weid, P. Oberson, \& N. Gisin, \\
\hline 4 & Rabu & Hidup & Hidup & Hidup & Hidup & OFDR," & Prosiding ECOC'00, 2000, paper 11.3.4. \\
\hline 5 & Kamis & Hidup & Hidup & Hidup & Mati & p. 10 S. & \\
\hline 6 & Jumat & Hidup & Hidup & Hidup & Hidspp & R. E Sorace, V & S. Reinhardt, \&S. A. Vaughn, "High- \\
\hline 7 & Sabtu & Hidup & Hidup & Hidup & Hidup & speed digital-to- $R$ & F converter," U.S. Patent 5668842 \\
\hline 8 & Minggu & Hidup & Hidup & Hidup & Mati & Sept. Siga 1 b97. & \\
\hline 9 & Senin & Hidup & Hidup & Hidup & Midij & (2002Sisa the & [Online].Tersedia: \\
\hline 10 & Selasa & Hidup & Hidup & Hidup & Hidup & http://www.ieee.o & g/ \\
\hline 11 & Rabu & Hidup & Hidup & Hidup & Hidulup & M. Shell. (2002) I & IEEEtran homepage on CTAN. [Online]. \\
\hline 12 & Kamis & Hidup & Hidup & Hidup & Mati & Tersestàa 12 & http://www.ctan.org/tex- \\
\hline 13 & Jumat & Hidup & Hidup & Hidup & Hidup & archive/macros/lat & tex/contrib/supported/IEEEtran/ \\
\hline 14 & Sabtu & Hidup & Hidup & Hidup & H\&up & FLEXChip Signa & Processor $(M C 68175 / D)$, Motorola, \\
\hline 15 & Minggu & Hidup & Hidup & Hidup & Mati & 1990. Sisa 10 & \\
\hline 16 & Senin & Hidup & Hidup & Hidup & H础 & sa & Opto Speed \\
\hline
\end{tabular}

\section{KESIMPULAN}

Shonicno (Smart Garden Home Aquaponic Based Arduino) merupakan terobosan inovatif dengan memanfaatkan teknologi arduino, dengan arduino sebagai otak dari Shonicno ini bisa memanfaatkan lahan sempit untuk budidaya tanaman dan ikan secara modern. Shonicno dapat berjalan dengan pengaturan sistem schedule, dapat memonitoring suhu dan kelembapan. Sistem penanaman akuaponik di terapkan dengan menggunakan pompa dan selang untuk menyedot air dari aquarium dan mengembalikan hasil filtering ke aquarium. Otomatisasi pemberian pakan ikan tiga kali sehari dengan jeda delapan jam dan penyinaran dilakukan dibawah suhu $35^{\circ}$ celcius.

\section{UCAPAN TERIMA KASIH}

Penulis mengucapkan terima kasih kepada Kementrian Riset Teknologi dan Perguruan Tinggi, Direktur Politeknik Negeri Jember yang telah memberikan dana untuk pelaksanaan penelitian program kreativitas mahasiswa.

\section{DAFTAR PUSTAKa}

[1] S. M. Metev \& V. P. Veiko, Laser Assisted Microtechnology, 2nd ed., R. M. Osgood, Jr., Ed. Berlin, Germany: Springer-Verlag, 1998.

[2] J. Breckling, Ed., The Analysis of Directional Time Series. Applications to Wind Speed and Direction, seri Lecture Notes in Statistics. Berlin, Germany: Springer, 1989, vol. 61. Keterangan

S. Zhang, C. Zhu, J. K. O. Sin, \&P. K. T. Mok, "A novel ultrathin elevated channel low-temperature poly-Si TFT,"

[10] A. Karnik, "Performance of TCP congestion control with rate feedback: TCP/ABR and rate adaptive TCP/IP," $\mathrm{M}$. Eng. thesis, Indian Institute of Science, Bangalore, India, Jan. 1999.

[11] J. Padhye, V. Firoiu, \&D. Towsley, "A stochastic model of TCP Reno congestion avoidance and control," Univ. of 
Jurnal Teknologi Informatika dan Terapan Vol. 05, No 01, Januari - Juni 2018 ISSN: 2354-838X

DOI: https://doi.org/10.25047/jtit.v5i1.75

Massachusetts, Amherst, MA, CMPSCI Tech. Rep. 99-02, 1999.

[12] Wireless LAN Medium Access Control (MAC) and Physical Layer (PHY) Specification, IEEE Std. 802.11, 1997. 
Shonicno (Smart Garden Home Aquaponic Based Arduino) 